
\title{
25 Research Soure \\ The effect of sinomenine eye drops on experimental mice dry eye
}

Hui Li

Department of Ophthalmology,The Shanghai Sixth People's Hospital East Campus

\section{Liang Yan}

Department of Ophthalmology,The Shanghai Sixth People's Hospital East Campus,Shanghai

Peirong Lu ( $\boldsymbol{D}$ lupeirong@suda.edu.cn )

https://orcid.org/0000-0002-1423-1737

\section{Research article}

Keywords: Dry eye, Dry eye syndrome, Sinomenine

Posted Date: February 6th, 2020

DOI: https://doi.org/10.21203/rs.2.22817/v1

License: (c) (i) This work is licensed under a Creative Commons Attribution 4.0 International License. Read Full License

Version of Record: A version of this preprint was published at Cutaneous and Ocular Toxicology on October 1st, 2020. See the published version at https://doi.org/10.1080/15569527.2020.1840580. 


\section{Abstract}

Background: To investigate the effect of topical sinomenine (SIN) on ocular surface damage in dry eye of experimental mice.

Study Design: Laboratory Investigation.

Methods: Experimental dry eye was created using scopolamine hydrobromide in female C57BL/6 mice. Eye drops consisting of $0.05 \%$, or $0.1 \%$ SIN or phosphate-buffered saline (PBS) were applied to the dry eye of experimental mice. Tear product and corneal staining scores were measured at 7 and 14 days after treatment. Interleukin (IL)-1 $\beta$ and tumour necrosis factor (TNF) - $a$ levels in the SIN groups at 14 days after treatment were compared with those of other groups.

Results: Mice treated with $0.05 \%$ or $0.1 \%$ SIN showed a significant improvement in tear product and corneal irregularity compared to the control and PBS-treated groups. A significant decrease in the levels of IL-1 $\beta$ and TNF- $a$ was observed in the $0.05 \%$ and $0.01 \%$ SIN-treated groups.

Conclusions: Topical SIN eye drop application can effectively improve clinical signs and decrease inflammation in the ocular surface, and alleviate ocular surface damage in dry eye.

\section{Background}

Dry eye is a commonly chronic disease of the tear fluid and ocular surface affecting $11-17 \%$ of the general population depending on the applied diagnostic criteria, the age of the population studied and geographic location (1-4)(5)(6-10). The symptoms of dry eye include discomfort, burning or foreign body sensation, irritation, itchy or painful eyes, visual disturbance and in some cases, even blindness. The aetiology for dry eye syndrome include insufficient tear production or increased evaporation of the tears, hyperosmolarity, and inflammatory response (11). Recent studies have shown that chronic inflammation stimulated by the activation of innate immunity, instability of the tear film, and the hyperosmolar tears play a key role in the development of ocular surface damage in dry eye patients $(2,4-6,11-13)$.

The management of dry eye includes environmental and behavioural modification, the use of artificial tears, eye drops or ointments, contact lenses, and surgery depending on disease severity $(14,15)$. Amongst the various treatment options, inflammation control in the lacrimal functional unit is the mainstream choice for treating dry eye based on the concept that inflammation is a major factor in the pathogenesis of dry eye (16). Recent studies have showed that treatment aimed at suppressing the ocular surface inflammation could effectively sustain ocular surface homeostasis, improve tear film stability, balance tear osmolality, and alleviate ocular discomfort.

Sinomeniumacutum (SIN) is a quinoline alkaloid and morphinan derivative extracted from the stems and roots of sinomeniumacutum. Since the main active component of SIN was isolated from this medicinal plant in the 1920s (17), it has been used extensively to treat immune-related disorders in pharmacological 
experimental animal models and clinical patients, such as for treating rheumatoid arthritis, arrhythmia, and neuralgia (18). SIN possesses anti-inflammatory and immunoregulatory properties, enhances macrophage phagocytosis and improve the immune response of macrophages by downregulating the expression of interleukin (IL)- 6 and tumour necrosis factor (TNF)- $a$ in the macrophage (19). Uveitis and dry eye syndrome are the two common ocular inflammatory diseases in which the main pathophysiological mechanisms are autoimmune and inflammatory. Song showed that topical administration of SIN in situ gel in rats could inhibit autoimmune uveitis(20), which make us to think about the effect of SIN on dry eye. However, to our knowledge, there is no study on this topic. Therefore, we aimed to investigate the effect of SIN on experimental dry eye in mice.

\section{Methods}

\section{Reagents}

Scopolamine hydrobromide (St. Louis, MO, USA) was dissolved in $0.9 \%$ sterilised $\mathrm{NaCl}$ solution at 6 $\mathrm{mg} / \mathrm{ml}$ prior to injections. Pure SIN (Beijing, China) was diluted to two concentrations $(0.05 \%$ and $1 \%)$ with phosphate-buffered saline (PBS), and the pH value was adjusted to 6.8-7.2. Then the solution was filtered by microporous membrane filtration and stored at $4{ }^{\circ} \mathrm{C}$. The whole pharmaceutical procedure was completed in the cell culture room.

\section{Animals}

The procedures used in this research were approved by the Experimental Animal Ethics Committee of Shanghai Jiao Tong University Affiliated Sixth People's hospital and performed in accordance with the National Institutes of Health Guide for the Use of Laboratory Animals. Female C57BL/6 mice (8 to 11 weeks, Shanghai SLAC Laboratory Animal Centre, Shanghai, China) were housed under relatively constant temperature $(25 \pm 1 \mathrm{C})$ and humidity conditions $(40 \pm 4 \%)$. The environment light-dark illumination cycle ( 8 am to $8 \mathrm{pm}$ ) is $12 \mathrm{~h}: 12 \mathrm{~h}$. Prior to the beginning of the study, all animals were fed with food and water and were acclimatised to the study environment for at least 1 week. The mice were examined by slit-lamp microscopy and corneal fluorescein staining. Only healthy mice with no cornel infections, and with total corneal fluorescein staining scores $<10$ were used in this study.

\section{Murine Dry Eye Model}

Mice received $0.1 \mathrm{ml}$ scopolamine hydrobromide by subcutaneous injections four times a day (8:00, $11: 00,15: 00,18: 00$ ) and were harboured in a controlled environment chamber at an ambient humidity less than $20 \%$ for 5 days to induce experimental dry eye (EDE). The age and gender matched group of mice received an equal volume of physiologic saline as the untreated (UT) group.

\section{Experimental procedure}

The mice with EDE were evaluated with tear product and cornea fluorescein staining (CFS) score as a EDE baseline condition, then were randomly assigned to four groups, with each group consisting of eight 
mice according to topical treatment: (1) EDE group mice which did not receive any eye drop treatment; (2) EDE+PBS group mice which were treated with PBS solution; (3) EDE+0.05\%SIN group mice which were treated with $0.05 \%$ preservative-free SIN hydrochloride eye drops; (4) EDE+1\% SIN group mice which were treated with $1 \%$ preservative-free SIN hydrochloride eye drops. UT group mice were treated with PBS solution. All groups received $5 \mu$ leye drops by topical application four times daily for 14 days in each eye. The eye drops were administered by one investigator throughout the study. Tear product and CFS score were measured under slit-lamp microscope at 7 (D7) and 14 days (D14) after treatment. In order to avoid the assessment bias, the treatments and the group allocation was blinded to the technician who treated the mice and to the researcher who assessed the outcome. The mice grouping was uncovered at the end of the analysis.

\section{Tear Product}

The amount of tears (16 eyes/ 8 mice in each group) was measured with phenol red thread tear test at the same time (8 PM) on D7 and D14. The subjects received no sedatives or anaesthetics. The eyelid was pulled down slightly and the thread was placed on the lower conjunctival fornix using forceps at approximately one-third of the lower eyelid distance from the lateral canthus for $15 \mathrm{~s}$. The wetted red portion of the thread was measured in millimetres under a slit-lamp biomicroscope (XL1, Shin-Nippon, Niigata, Japan) to maximise accuracy. The final length was averaged from the three times measurements in each eye.

\section{Corneal fluorescein staining}

Corneal epithelial staining was graded under a slit-lamp microscope at 90 seconds after tear collection. The cornea was divided into four quadrants, and the damage in each quadrant was scored respectively according to the following rules: $0=$ absent; $1=$ slightly punctate staining with less than 30 spots; 2 = punctate staining with more than 30 spots but without diffuse staining; 3 = severe and diffuse staining but without positive plaque; 4 = positive fluorescein plaque. The scores of each quadrant were summed to represent the damage on each cornea.

\section{Inflammatory Responses}

Mice were euthanized by intraperitoneal injection of sodium pentobarbital $(200 \mathrm{mg} / \mathrm{kg})$ and the mice conjunctiva was surgically excised and then total RNA from conjunctivas was extracted and pooled from two eyes of the same experimental group using the RNA isolation kit according to the manufacturer's instructions (PicoPure RNA isolation kit; Applied Biosystem, Foster City, CA). cDNA was synthesised using a reverse transcription kit (Catalogue no. RR047A; TaKaRa, Shiga, Japan) from $1 \mu \mathrm{g}$ total RNA using random primers and Moloney Murine Leukaemia Virus. The expression of IL- $1 \beta$ and TNF- $\alpha$ and glyceraldehyde-3-phosphate dehydrogenase (GAPDH) was evaluated by qRT-PCR. The primer sequences for qRT-PCR detection of IL-1 $\beta$, TNF- $\alpha$ and GAPDH are listed in the Table 1. qRT-PCR amplification programme included an initial denaturation step at $95^{\circ} \mathrm{C}$ for 10 minutes, followed by 40 cycles for 10 seconds, and 60 cycles for 30 seconds. The RNA concentration was measured at $260 \mathrm{~nm}$ and stored at 
$-80^{\circ} \mathrm{C}$ before use. The qRT-PCR results were analysed using the comparative threshold cycle method and normalised with GAPDH as an endogenous reference.

\section{Statistical analysis}

All data was expressed as Mean \pm SD. Statistical analyses were performed with SPSS 20 (IBM Inc.). The data were analysed by one-way ANOVA followed by post hoc test. $p<0.05$ was considered significant.

\section{Results}

\section{Dry eye induction}

All the mice including the mice in the UT group and the EDE mice were healthy before sacrificed. Five days after the induction of EDE, all EDE mice $(n=32)$ showed significantly decreased tear production compared to the UT group ( $n=8)$ (Figure 1 ; UT vs. EDE, $6.03 \pm 0.63 \mathrm{~mm}$ vs. $3.25 \pm 0.57 \mathrm{~mm}, p<0.05$ ). The corneal staining scores were significantly higher in EDE mice compared to those of the UT group (Figure 2 ; UT vs. EDE, $1.5 \pm 0.53,12.13 \pm 2.17, p<0.05)$. These confirmed that the EDE model was successfully established.

\section{Effects of topical application of SIN on tear production}

The phenol red thread test was used to assess the effect of SIN eye drops on tear production in EDEinduced mice in our study. After 7 days and 14 days of treatment, the tear production in the EDE and EDE+PBS groups did not change compared to the pre-treatment values (Figure $1 ; 3.25 \pm 0.57 \mathrm{~mm}, 3.24$ $\pm 0.73 \mathrm{~mm}$ and $3.28 \pm 0.48 \mathrm{~mm}$ for the EDE group before treatment and 7 and 14 days after treatment, respectively, $p>0.05 ; 3.24 \pm 0.73 \mathrm{~mm}, 3.26 \pm 0.64 \mathrm{~mm}$ and $3.30 \pm 0.62 \mathrm{~mm}$ for EDE + PBS group before treatment, 7 days and 14 days after treatment respectively, $p>0.05$ ). After 7 days and 14 days of treatment, the tear production in the EDE $+0.05 \%$ SIN treatment group and the EDE + 0.1\% SIN treatment group was gradually increased compared to the pre-treatment values. In the EDE $+0.05 \%$ SIN treatment group, the difference between pre-treatment values and post-treatment values after 14 days was significant (Figure 1, 3.31 $\pm 0.60 \mathrm{~mm}$ vs. $4.19 \pm 0.67 \mathrm{~mm}, p<0.05$ ), but the difference between pre-treatment values and post-treatment values after 7 days was not significant (Figure 1, $3.31 \pm 0.60 \mathrm{~mm}$ vs. $3.75 \pm 0.40$ $\mathrm{mm}, p>0.05$ ); same was observed for post-treatment values after 7 days and after 14days (Figure 1 , $3.75 \pm 0.40 \mathrm{~mm}$, vs. $4.19 \pm 0.67 \mathrm{~mm} p>0.05)$. In the EDE $+0.1 \%$ SIN treatment group, the differences between any two time points were statistically significant (Fig. 1, $3.33 \pm 0.56 \mathrm{~mm}, 3.99 \pm 0.37 \mathrm{~mm}$ and $4.81 \pm 0.60 \mathrm{~mm}$, for before treatment, 7 days after treatment and 14 days after treatment respectively, all $p$ $<0.05)$.

\section{Effects of topical application of SIN on corneal fluorescein staining scores}

Fluorescein staining was used to assess the effect of SIN eye drops on the changes in corneal epithelial integrity in this study. Five days after the induction of EDE, the corneal staining scores were significantly higher in EDE, EDE + PBS, EDE + $0.05 \%$ SIN and EDE + 1\% SIN groups compared to those of the UT group 
(Figure. $1 ; 1.5 \pm 0.53,12.13 \pm 2.17,11.88 \pm 1.81,11.75 \pm 2.05,12.13 \pm 1.64$ for UT, EDE, EDE+PBS, EDE+0.05\% SIN and EDE $+1 \%$ SIN groups respectively; all $p<0.05)$.

After 7 days and14 days of treatment, the corneal staining scores in the EDE and EDE+PBS groups did not change compared to the pre-treatment scores (Figure. $2 ; 12.13 \pm 2.17,12.75 \pm 2.49$, and $11.75 \pm 2.38$ for EDE group before treatment, at 7 days and 14 days after treatment, respectively, $p>0.05 ; 11.88 \pm 1.81$, $12.50 \pm 2.27$, and $12.25 \pm 2.12$ for EDE+PBS group before treatment, at 7 days and 14 days after treatment, respectively, $p>0.05$ ). After 7 days and 14 days of treatment, the staining scores in the EDE $+0.05 \% \mathrm{SIN}$ treatment group and the EDE $+0.1 \%$ SIN treatment group gradually decreased compared to the pretreatment scores. In the EDE $+0.05 \%$ SIN treatment group, the difference between the scores before treatment and 14 days after treatment was significant (Figure 2, $11.75 \pm 2.05$ vs. $7.63 \pm 1.92, p<0.05$ ); however, differences between the scores before treatment and 7 days after treatment (Figure 2 , $11.75 \pm 2.05$ vs $9.75 \pm 2.82 ., p>0.05$ ), and between 7 days after treatment and 14 days after treatment was not significant (Figure $2,9.75 \pm 2.82$ vs. $7.63 \pm 1.92, p>0.05$ ). In the $E D E+0.1 \% \mathrm{SIN}$ treatment group, the differences between any two time points were statistically significant (Figure 2, 12.13 $\pm 1.64,7.63 \pm 1.92$ and $5.00 \pm 2.20$ for before treatment, 7 days after treatment and 14 days after treatment respectively, all $p$ $<0.05)$.

\section{Changes in cytokine levels in cornea after SIN treatment}

Following the induction of EDE, SIN eye drops were topically given to the mice and inflammatory cytokine levels in the cornea were determined by quantitative RT-PCR on day 14 after the mice were sacrificed. Among the cytokines evaluated, expressions of TNF- $a$ and IL-1 $\beta$ on the ocular surfaces in EDE $+0.05 \%$ SIN group and in EDE + 1\% SIN group decreased in a dose-dependent manner compared to that before treatment (Figure 3 and Figure 4). However, statistical analysis showed that the levels of IL-1 $\beta$ in the mice treated with two doses of SIN decreased significantly. The levels of TNF-a decreased only in the mice treated with $0.1 \%$ SIN eye drops but not in those treated with $0.05 \%$ SIN.

\section{Discussion}

Dry eye is a chronic ocular surface disease and can cause a visual disorder affecting the quality of life in serious dry eye. Dry eye is complexed by tear film destabilization and tear production decrease resulting from immoderate vaporization of tears on the ocular surface(21). The continued imbalance between the tear film and tear production results in gradual dysfunction of the lacrimal glands and damage of the corneal epithelial cells $(16,22-25)$. It has been reported that long-term dry eye increased inflammatory response and expression of inflammatory cytokines such as intercellular adhesion molecule-1, TNFa,vascular cell adhesion molecule-1 chemokines and their receptors on the ocular surface of dry eye (2630). 
Topical anti-inflammatory agents, such as corticosteroids and cyclosporine A could improve symptoms and ocular surface damage by inhibiting inflammation on the ocular surface and lacrimal gland (31-33). SIN, a new anti-inflammatory and immuno-suppressive agent, has been reported to treat rheumatoid arthritis and chronic glomerulonephritis $(34,35)$. The exact mechanism of SIN on the immune disease is not clear. The possible mechanism included inhibition of inflammatory mediator secretion and reduction of immune complex generation. For example, SIN was found to reduce the synthesis of leukotriene $\mathrm{C} 4$, nitric oxide, prostaglandin E3, and TNF-a in vitro as well as in vivo and to reduce the mRNA expression of proinflammatory cytokines in rats with adjuvant arthritis $(36,37)$.

The lacrimal functional unit is composed of the ocular surface epithelium and lacrimal gland and is the target of the immune system in dry eye pathology (38). Studies have shown that the cytokines such as IL6, IL-17 and chemokine ligand 2 in lacrimal gland tissues are involved in immune and inflammatory responses. They could impair lacrimal gland secretion by directly inhibiting neural activity or neurotransmitter release $(39,40)(41)$. Inhibition of these cytokines could inhibit the immune and inflammatory response to improve dry eye disease signs (42).

The present findings show that topical application of SIN eye drops results in an improvement in clinical signs indicated by increased tear production and decreased corneal staining scores and a significant decrease of inflammation factor (IL-1 $\beta$ and TNF- $\alpha$ ) in the ocular surface of EDE compared to the controls. Tear production was higher and corneal surface irregularity scores were lower, in $0.05 \%$ and $0.1 \%$ SINtreated mice than in EDE and PBS-treated mice. IL-1 $\beta$ and TNF- $a$ expression in the conjunctivae were significantly lower in $0.05 \%$ and $0.1 \%$ SIN-treated mice than in EDE and PBS-treated mice. These finding showed that topical application of SIN eye drops could improve the tear film and ocular surface parameters by inhibiting inflammatory cytokines in the conjunctiva.

Dry eye has a frequent recurrence and needs long-term treatment. It has been confirmed that systemic application of SIN for 2 weeks in vivo has no obvious side effects in this study. The limitation of this study includes the short-term treatment and observation. Further research is necessary to investigate the safety of long-term use of SIN eye drops on the ocular surface in dry eye patients.

\section{Conclusions}

This study provides evidence that the application of $0.05 \%$ and $0.1 \%$ SIN eye drops could improve tear production and effectively alleviate ocular surface irregularities and reduce inflammatory cytokines on the ocular surface in mouse EDE model. Our results suggest that topical application of SIN is useful in the treatment of dry eye disease. Maybe we could verify the outcome on the patients with dry eye in the future.

\section{Abbreviations}

EDE 
Experimental dry eye; SIN:sinomenine; IL:interleukin; TNF-a:tumour necrosis factor-a;

GAPDH:glyceraldehyde-3-phosphate dehydrogenase; CFS:cornea fluorescein staining; UT:untreated;

PBS:phosphate-buffered saline.

\section{Declarations}

\section{Ethics approval and consent to participate}

All animal experiments were approved by the animal ethical committee of the Shanghai Jiao Tong University Affiliated Sixth People's Hospital, and performed in accordance with the National Institutes of Health Guide for the Use of Laboratory Animals (43).

\section{Consent for publication}

Not applicable.

\section{Availability of data and materials}

The datasets used and analysed during the current study are available from the corresponding author on reasonable request.

\section{Competing interests}

The authors declare that they have no competing interests.

\section{Funding}

This research was supported by the grant from the Seed Grant from Shanghai Health Medical School (HMSF-16-21-013) to Hui Li. However, the funders had no role in study design, data collection and analysis, decision to publish, or preparation of the manuscript.

\section{Authors' contributions}

PL designed the study, collected data, and wrote the paper. HL collected data and wrote the paper. LY conceived the idea and interpreted results; All authors read and approved the submission of this manuscript.

\section{Acknowledgements:}

None.

\section{References}


1.

Schein OD, Munoz B, Tielsch JM, Bandeen-Roche K, West S. Prevalence of dry eye among the elderly. Am J Ophthalmol. 1997;124(6):723-8.

2.

Brewitt H, Sistani F. Dry eye disease: the scale of the problem. Surv Ophthalmol. 2001;45(Suppl 2):199202.

3.

Bjerrum KB. Keratoconjunctivitis sicca and primary Sjogren's syndrome in a Danish population aged 3060 years. Acta Ophthalmol Scand. 1997;75(3):281-6.

4.

Schein OD, Hochberg MC, Munoz B, Tielsch JM, Bandeen-Roche K, Provost T, Anhalt GJ, West S. Dry eye and dry mouth in the elderly: a population-based assessment. Arch Intern Med. 1999;159(12):1359-63. 5 .

Bandeen-Roche K, Munoz B, Tielsch JM, West SK, Schein OD. Self-reported assessment of dry eye in a population-based setting. Invest Ophthalmol Vis Sci. 1997;38(12):2469-75.

6.

Moss SE, Klein R, Klein BE. Prevalence of and risk factors for dry eye syndrome. Arch Ophthalmol. 2000;118(9):1264-8.

7.

Albietz JM. Prevalence of dry eye subtypes in clinical optometry practice. Optom Vis Sci. 2000;77(7):357-63.

8.

Caffery BE, Richter D, Simpson T, Fonn D, Doughty M, Gordon K. CANDEES. The Canadian Dry Eye Epidemiology Study. Adv Exp Med Biol. 1998;438:805-6.

9.

Doughty MJ, Fonn D, Richter D, Simpson T, Caffery B, Gordon K. A patient questionnaire approach to estimating the prevalence of dry eye symptoms in patients presenting to optometric practices across Canada. Optom Vis Sci. 1997;74(8):624-31.

10.

Hikichi T, Yoshida A, Fukui Y, Hamano T, Ri M, Araki K, Horimoto K, Takamura E, Kitagawa K, Oyama M, et al. Prevalence of dry eye in Japanese eye centers. Graefes Arch Clin Exp Ophthalmol. 1995;233(9):555-8. 11.

Stevenson W, Chauhan SK, Dana R. Dry eye disease: an immune-mediated ocular surface disorder. Arch Ophthalmol. 2012;130(1):90-100.

12.

Stern ME, Schaumburg CS, Pflugfelder SC. Dry eye as a mucosal autoimmune disease. Int Rev Immunol. 2013;32(1):19-41.

13.

Goyal S, Chauhan SK, El Annan J, Nallasamy N, Zhang Q, Dana R. Evidence of corneal lymphangiogenesis in dry eye disease: a potential link to adaptive immunity? Arch Ophthalmol. 
2010;128(7):819-24.

14.

Behrens A, Doyle JJ, Stern L, Chuck RS, McDonnell PJ, Azar DT, Dua HS, Hom M, Karpecki PM, Laibson PR, Lemp MA, Meisler DM, Del Castillo JM, O'Brien TP, Pflugfelder SC, Rolando M, Schein OD, Seitz B, Tseng SC, van Setten G, Wilson SE, Yiu SC. Dysfunctional tear syndrome: a Delphi approach to treatment recommendations. Cornea. 2006;25(8):900-7.

15.

Gupta H, Jain S, Mathur R, Mishra P, Mishra AK, Velpandian T. Sustained ocular drug delivery from a temperature and pH triggered novel in situ gel system. Drug Deliv. 2007;14(8):507-15.

16.

Oh HN, Kim CE, Lee JH, Yang JW. Effects of Quercetin in a Mouse Model of Experimental Dry Eye. Cornea. 2015;34(9):1130-6.

17.

Yamasaki H. Pharmacology of sinomenine, an anti-rheumatic alkaloid from Sinomenium acutum. Acta Med Okayama. 1976;30(1):1-20.

18.

Xu M, Liu L, Qi C, Deng B, Cai X. Sinomenine versus NSAIDs for the treatment of rheumatoid arthritis: a systematic review and meta-analysis. Planta Med. 2008;74(12):1423-9.

19.

Wang AL, Li Z, Yuan M, Yu AC, Zhu X, Tso MO. Sinomenine inhibits activation of rat retinal microglia induced by advanced glycation end products. Int Immunopharmacol. 2007;7(12):1552-8.

20.

Song J, Bi H, Xie X, Guo J, Wang X, Liu D. Preparation and evaluation of sinomenine hydrochloride in situ gel for uveitis treatment. Int Immunopharmacol. 2013;17(1):99-107.

21.

Lemp MA. Report of the National Eye Institute/Industry workshop on Clinical Trials in Dry Eyes. CLAO J. 1995;21(4):221-32.

22.

Situ P, Simpson TL, Fonn D, Jones LW. Conjunctival and corneal pneumatic sensitivity is associated with signs and symptoms of ocular dryness. Invest Ophthalmol Vis Sci. 2008;49(7):2971-6.

23.

Rolando M, Zierhut M. The ocular surface and tear film and their dysfunction in dry eye disease. Surv Ophthalmol. 2001;45(Suppl 2):203-10.

24.

Kim CE, Oh HN, Lee JH, Yang JW. Effects of chondrocyte-derived extracellular matrix in a dry eye mouse model. Mol Vis. 2015;21:1210-23.

25.

Messmer EM. The pathophysiology, diagnosis, and treatment of dry eye disease. Dtsch Arztebl Int. 2015;112(5):71-81. quiz 82.

26. 
Calonge M, Enriquez-de-Salamanca A, Diebold Y, Gonzalez-Garcia MJ, Reinoso R, Herreras JM, Corell A. Dry eye disease as an inflammatory disorder. Ocul Immunol Inflamm. 2010;18(4):244-53.

27.

Enriquez-de-Salamanca A, Castellanos E, Stern ME, Fernandez I, Carreno E, Garcia-Vazquez C, Herreras $\mathrm{JM}$, Calonge M. Tear cytokine and chemokine analysis and clinical correlations in evaporative-type dry eye disease. Mol Vis. 2010;16:862-73.

28.

Galbis-Estrada C, Pinazo-Duran MD, Cantu-Dibildox J, Marco-Ramirez C, Diaz-Llopis M, Benitez-delCastillo J. Patients undergoing long-term treatment with antihypertensive eye drops responded positively with respect to their ocular surface disorder to oral supplementation with antioxidants and essential fatty acids. Clin Interv Aging. 2013;8:711-9.

29.

Pinazo-Duran MD, Galbis-Estrada C, Pons-Vazquez S, Cantu-Dibildox J, Marco-Ramirez C, Benitez-delCastillo J. Effects of a nutraceutical formulation based on the combination of antioxidants and omega-3 essential fatty acids in the expression of inflammation and immune response mediators in tears from patients with dry eye disorders. Clin Interv Aging. 2013;8:139-48.

30 .

Brignole F, Pisella PJ, Goldschild M, De Saint Jean M, Goguel A, Baudouin C. Flow cytometric analysis of inflammatory markers in conjunctival epithelial cells of patients with dry eyes. Invest Ophthalmol Vis Sci. 2000;41(6):1356-63.

31.

Palmer SL, Bowen PA 2nd, Green K. Tear flow in cyclosporine recipients. Ophthalmology. 1995;102(1):118-21.

32.

Matsuda S, Koyasu S. Mechanisms of action of cyclosporine. Immunopharmacology. 2000;47(23):119-25.

33.

Pflugfelder SC. Antiinflammatory therapy for dry eye. Am J Ophthalmol. 2004;137(2):337-42. 34.

Liu L, Buchner E, Beitze D, Schmidt-Weber CB, Kaever V, Emmrich F, Kinne RW. Amelioration of rat experimental arthritides by treatment with the alkaloid sinomenine. Int $\mathrm{J}$ Immunopharmacol. 1996;18(10):529-43.

35.

Wang Y, WANG PX, Li XJ. The effect of sinomenine on cyclooxygenase activity and the expression of COX-1 and COX-2 mRNA in human peripheral monocytes. Zhongguo Zhong Yao Za Zhi. 2003;28:352-5. 36.

Wang Y, Fang Y, Huang W, Zhou X, Wang M, Zhong B, Peng D. Effect of sinomenine on cytokine expression of macrophages and synoviocytes in adjuvant arthritis rats. J Ethnopharmacol. 2005;98(12):37-43.

37. 
Liu L, Riese J, Resch K, Kaever V. Impairment of macrophage eicosanoid and nitric oxide production by an alkaloid from Sinomenium acutum. Arzneimittelforschung. 1994;44(11):1223-6.

38.

Stern ME, Gao J, Siemasko KF, Beuerman RW, Pflugfelder SC. The role of the lacrimal functional unit in the pathophysiology of dry eye. Exp Eye Res. 2004;78(3):409-16.

39.

Pitcher JD 3rd, De Paiva CS, Pelegrino FS, McClellan AJ, Raince JK, Pangelinan SB, Rahimy E, Farley WJ, Stern ME, Li DQ, Pflugfelder SC. Pharmacological cholinergic blockade stimulates inflammatory cytokine production and lymphocytic infiltration in the mouse lacrimal gland. Invest Ophthalmol Vis Sci. 2011;52(6):3221-7.

40.

Luo L, Li DQ, Doshi A, Farley W, Corrales RM, Pflugfelder SC. Experimental dry eye stimulates production of inflammatory cytokines and MMP-9 and activates MAPK signaling pathways on the ocular surface. Invest Ophthalmol Vis Sci. 2004;45(12):4293-301.

41.

Song XJ, Li DQ, Farley W, Luo LH, Heuckeroth RO, Milbrandt J, Pflugfelder SC. Neurturin-deficient mice develop dry eye and keratoconjunctivitis sicca. Invest Ophthalmol Vis Sci. 2003;44(10):4223-9. 42.

Choi W, Noh H, Yeo A, Jang H, Ahn HK, Song YJ, Lee HK. The Effect of TNF-alpha Blocker HL036337 and Its Best Concentration to Inhibit Dry Eye Inflammation. Korean J Ophthalmol. 2016;30(4):302-8.

43.

$\mathrm{NIH}$ (National Institutes of Health U.S.A). Guide for the care and use of laboratory animals. Washington, D.C.: The National Academics Press; 2011.

\section{Table 1}

Table 1. The primer sequences used for qRT-PCR

\begin{tabular}{ccc}
\hline Gene & Forward Primer, 5'-3' & Reverse Primer, 3'-5' \\
\hline IL-1 $\beta$ & TGAGCTGAAAGCTCTCCACC & CTGATGTACCAGTTGGGGAA \\
TNF- $\alpha$ & TCTACTGAACTTCGGGGTGATCG & ACGTGGGCTACAGGCTTGTCA \\
GAPDH & TGTCCGTCGTGGATCTGAC & CCTGCTTCACCACCTTCTTG \\
\hline
\end{tabular}

\section{Figures}




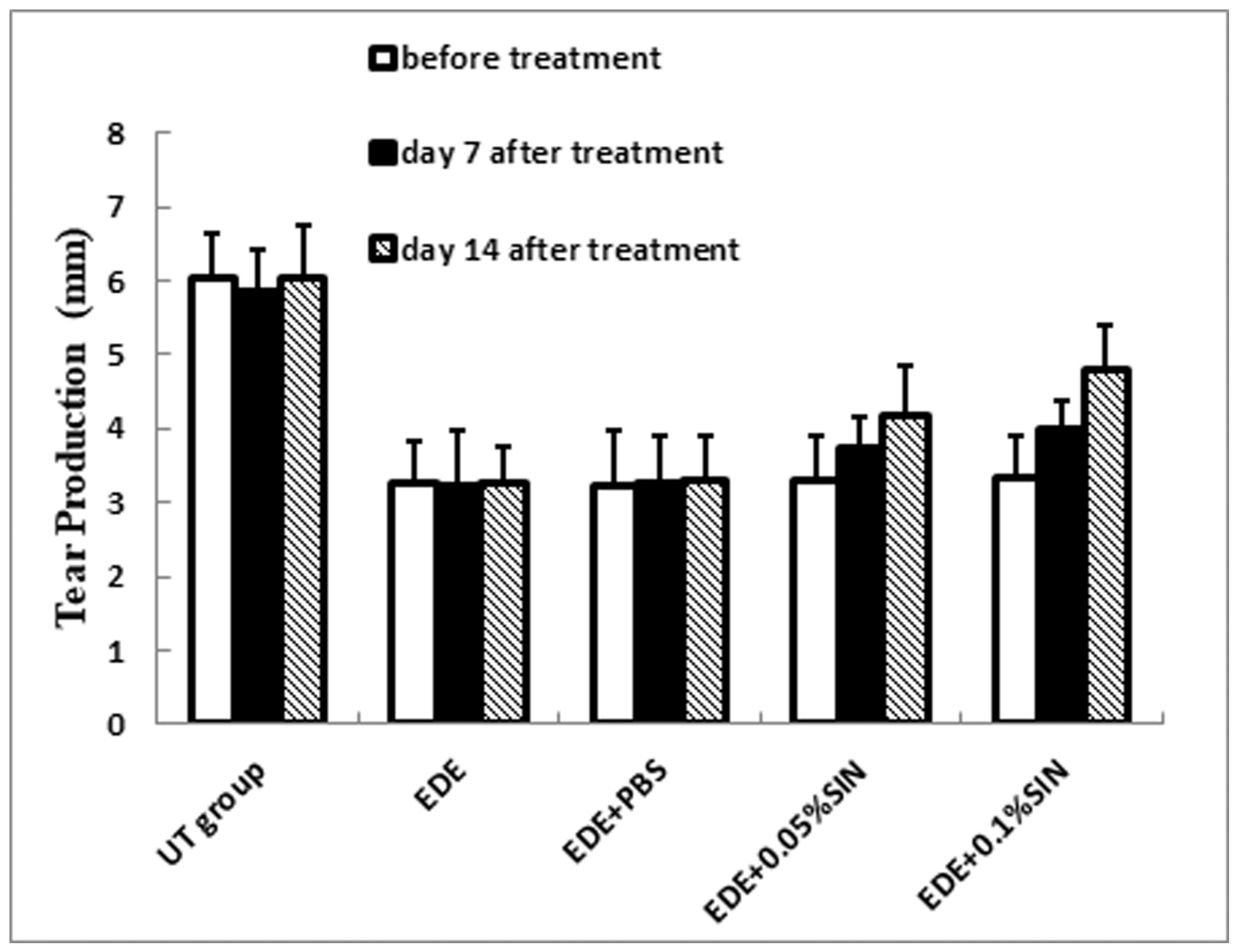

Figure 1

Effects of topical application of SIN on ocular surface damage in experimental mice with dry eye, evaluated by phenol red cotton test for the quantification of tear production. Data shown as mean $\pm \mathrm{SD}$. * $\mathrm{p}<0.05$. 


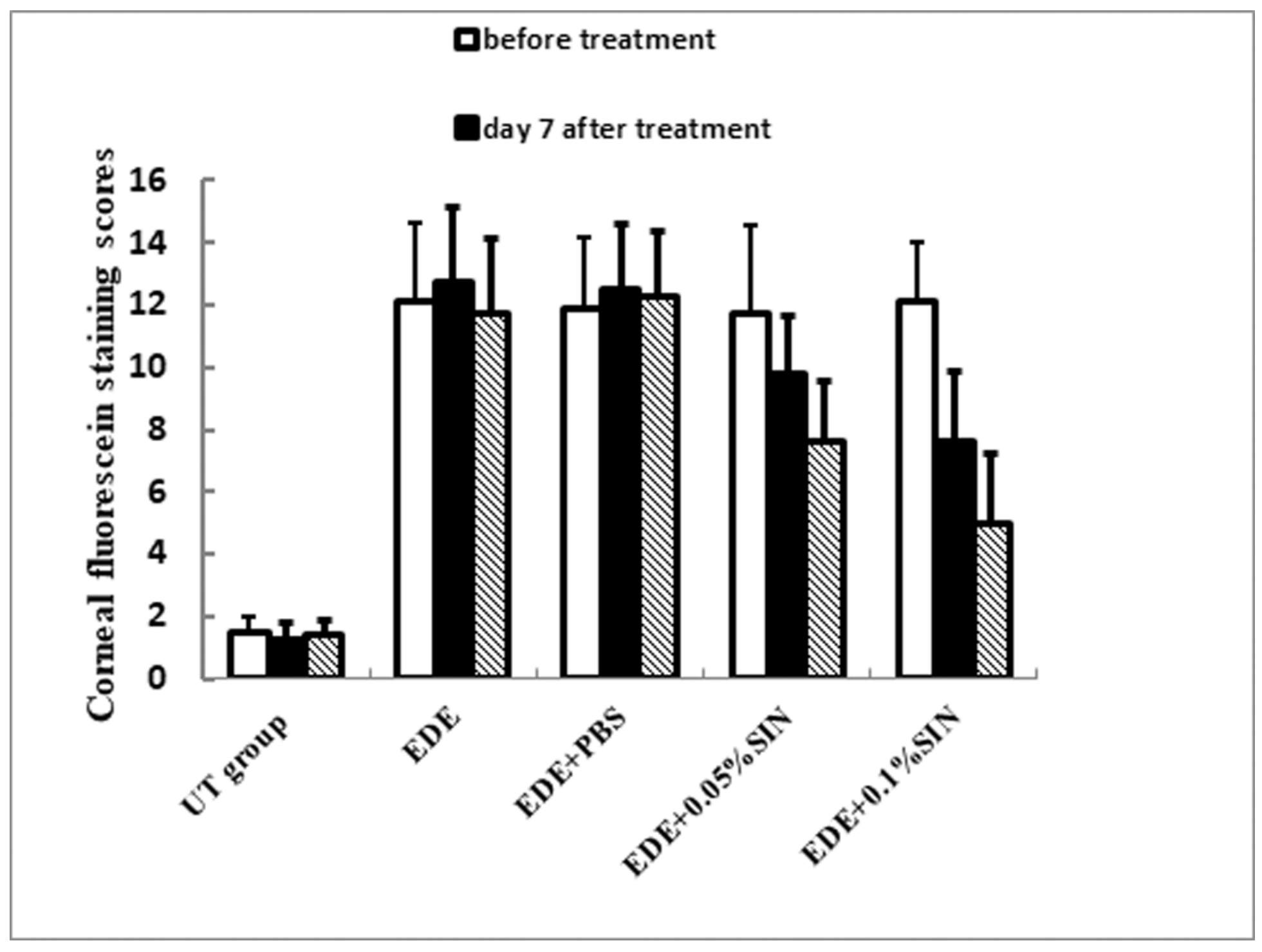

Figure 2

Mean corneal fluorescein staining scores in the untreated (UT) control, experimental dry eye (EDE), $0.05 \%$ sinomenine (SIN) treated, and $0.1 \%$ SIN-treated groups before treatment and 7 and 14 days after treatment. Data shown as mean $\pm \mathrm{SD}$. ${ }^{*} \mathrm{p}<0.05$. 


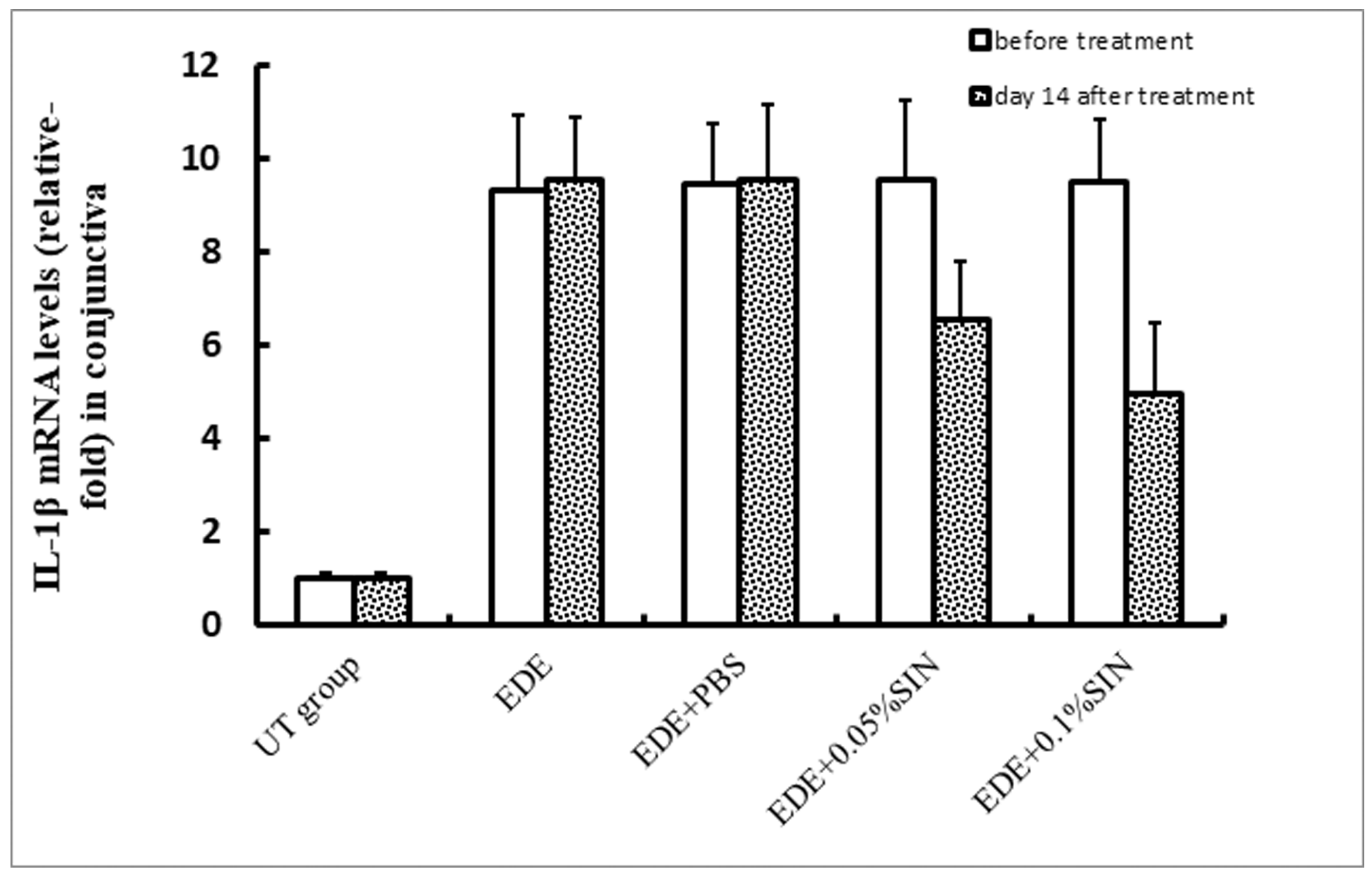

Figure 3

Real-time PCR analysis of IL-1 $1 \beta$ expression in mice. * significant difference when compared with pretreatment values $(p<0.05, n=8)$. Error bars represent $S D$. 


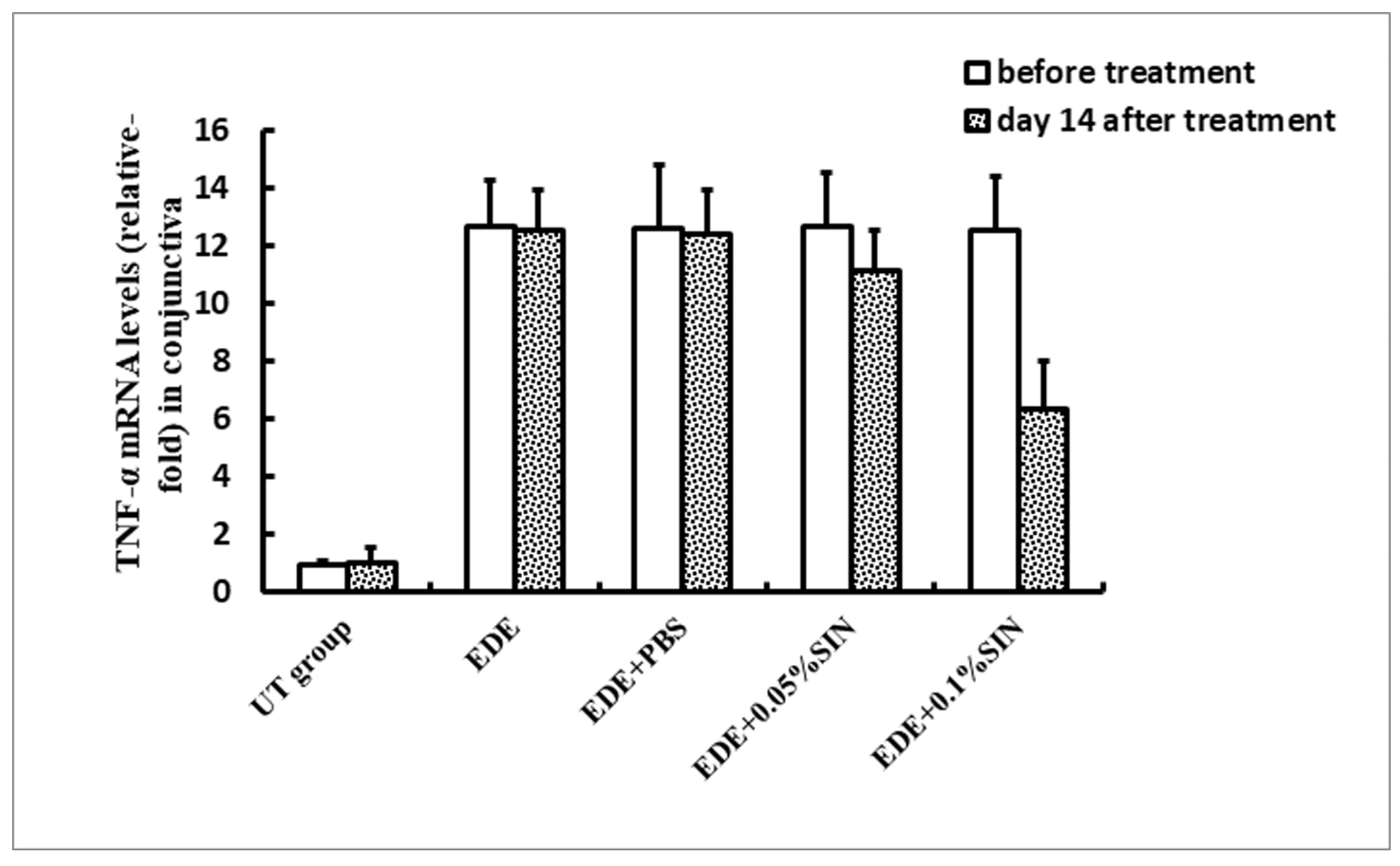

Figure 4

Real-time PCR analysis of TNF- $a$ expression in mice. * significant difference when compared with pretreatment values $(p<0.05, n=8)$. Error bars represent $S D$.

\section{Supplementary Files}

This is a list of supplementary files associated with this preprint. Click to download.

- NC3RsARRIVEGuidelinesChecklist.pdf 